\title{
"My" Losing Proposition: The Role of Ownership in Sunk Cost Effects: An Abstract
}

\author{
Stephan Dickert, Bernadette Kamleitner, Sophie Süssenbach, \\ and Erdem Geveze
}

\begin{abstract}
Sunk costs refer to investments that have been made that are irrecoverable and lost to the investor. The influence of sunk costs on economic decision making is pervasive and can be witnessed in a variety of domains including financial investments and consumption choices. Sunk costs compel consumers to "throw good money after bad money" even though the chances of making a profit or recovering the initial investments have disappeared and better options are available. The dominant explanations for sunk cost effects are related to loss and waste aversion (i.e., the tendency of people to dislike the feeling of having lost money or wasted effort). However, loss aversion might not be the only way to explain sunk cost effects. The current paper suggests that psychological ownership (i.e., the feeling that something is yours) can also explain the underlying dynamics that lead to sunk cost effects. We present two studies that critically investigate how psychological ownership changes in relation to increasing investments. Results from both studies demonstrate strong sunk cost effects, such that participants were much more likely to continue investing into the target project when more money had already been invested. Additionally, the results also showed that both psychological ownership and feelings related to loss aversion (anticipated pain) increased as higher amounts of money had been invested into the project. A serial mediation analysis revealed that higher levels of investment lead to greater psychological ownership, which in turn predicts greater anticipated pain from not completing the project. Finally, these feelings predict participants' sunk cost decisions. These results show that the effects of sunk costs operate through psychological ownership for consumer projects.
\end{abstract}

References Available Upon Request

\footnotetext{
S. Dickert $(\bowtie)$

Queen Mary University of London, London, UK

e-mail: s.dickert@qmul.ac.uk

B. Kamleitner • S. Süssenbach • E. Geveze

WU Vienna University of Economics and Business, Vienna, Austria

e-mail: bernadette.kamleitner@wu.ac.at; sophie.suessenbach@wu.ac.at; erdemgeveze@gmx.de

(C) Academy of Marketing Science 2018

N. Krey, P. Rossi (eds.), Back to the Future: Using Marketing Basics to Provide

Customer Value, Developments in Marketing Science: Proceedings of the

Academy of Marketing Science, DOI 10.1007/978-3-319-66023-3_182
} 